\title{
A recepção espanhola de Nietzsche nos últimos quarenta anos*
}

\author{
Diego Sánchez Meca**
}

\begin{abstract}
Resumo: o artigo analisa a recepção do pensamento de Nietzsche na Espanha nos últimos quarenta anos, mostrando as muitas vertentes pelas quais a obra do filósofo foi lida e as muitas influências que ela exerceu, como na política, na estética e nas artes. Num primeiro momento, a análise apresenta muitos autores que leram Nietzsche e mostra como a cada momento as ideias do filósofo eram invocadas em busca de renovação, sejam elas morais, estéticas ou políticas. Num segundo momento, traz à luz os estudos acadêmicos e a diversidade de temas da filosofia nietzschiana neles abordados.
\end{abstract}

Palavras-chave: recepção - Nietzsche - Espanha - interpretação

\section{A recepção de Nietzsche na Espanha até 1980}

A recepção do pensamento e da obra de Nietzsche no mundo hispânico tem sido muito bem tratada e estudada por Gonzalo Sobejano em seu livro Nietzsche na Espanha1, em relação ao período que parte do início desta recepção até o final da guerra civil. Sobejano analisa pormenorizadamente por que e de que modo houve o interesse e a influência de Nietzsche neste período em uma ampla quantidade de autores, documentando sua análise de modo competente e exaustivo. Como mostra o autor, no plano político,

\footnotetext{
* Tradução de Hélio Simões.

** Professor da Universidade de Madrid (UNED), Madrid, Espanha. E-mail: dsanchez@ fsof.uned.es.

1 SOBEJANO, G. Nietzsche na Espanha. Madrid: Gredos, 1967.
} 
Meca, D. S.

o marco desta recepção inicial foi constituído pelo movimento regeneracionista que surgiu a partir da perda de Cuba, a última colônia do Império Espanhol, e que, com uma profunda consciência da decadência da Espanha, tratava de impulsionar um maior nível cultural e uma melhor integração do nosso país na Europa. No plano estético-literário, esse movimento de renovação recebeu o nome de modernismo, enquanto no plano mais estritamente filosófico e pedagógico se polarizou, mais que em nenhum outro lugar, no Krausismo, introduzido por Julián Sanz del Río e difundido pela Institución Livre de Enseñanza. Esse complexo marco intelectual e ideológico fez seguramente com que, entre as ideias nietzschianas, se prestasse mais atenção às que melhor sintonizavam com o impulso de renovação com o qual, como um denominador comum de todos esses movimentos, se pretendia sair rapidamente da profunda prostração da Espanha no aspecto cultural, político e econômico: a afirmação da vida como vontade de potência, a exaltação da nobreza e do espírito de autossuperação em oposição ao pessimismo, ao nivelamento e a inércia da ordem social existente, e o espírito crítico que enfrenta o tradicionalismo petrificado em dogmas religiosos, metafísicos e políticos e trata de abrir ambiciosas perspectivas de um futuro melhor. Nietzsche entusiasma, portanto, muitos jovens dessa época - animados e ávidos de um espírito diligente de renovação - por sua característica exaltação da vontade, com que se crê capaz de empreender grandes realizações em vez de paralisar-se pelo pessimismo e pela negação de vida tal como propunha Schopenhauer. Concretamente, apreciava-se na ideia de além-do-homem essa ideia mesma de superação, que está inseparavelmente ligada à mudança de valores, às novas tábuas e à nova moral do homem seleto que devia ser implantada mediante uma crítica que generalizasse uma forte resistência ao convencional, ao tradicionalismo que se convertera em mesquinho disfarce de falso amor pela grandeza do passado.

Foi recebido, em última instância, um Nietzsche "vitalista", não só no sentido biológico do termo, mas também culturalista, pois 
o cultural é aqui interpretado como expressão ou projeção de ideias vitais, obras literárias e artísticas ou empresas culturais e políticas. Assim é manifestado no primeiro escrito publicado em castelhano sobre Nietzsche, escrito por Joan Maragall em 1893, no qual apresenta Nietzsche como o defensor de uma nova ideia de liberdade e de abertura a um novo futuro por construir:

Nietzsche vem afirmando o livre-arbítrio, a vontade como grande agente impulsor da vida. Na essência dos seres - afirma Nietzsche não há causas nem influências, nem meios ambientes, nem necessidades que valham: a vontade de cada um é sua causa e seu meio, e a lei de sua existência².

Outro catalão, Pompeu Gener, confessa ser partidário de Nietzsche "por seu culto apaixonado à vida e seu convencimento profundo de que todo o cristianismo tem sido uma obra de morte, anti-humanitária e que seria destruído"3. Mesmo aqueles que não veem Nietzsche com simpatia, se fixam nas mesmas ideias, ainda que estas mereçam uma avaliação dissemelhante. Assim, por exemplo, Ricardo Becerro de Bengoa, que, para desacreditar Nietzsche, o trata como um pobre enfermo mental, o associa com Stirner e impugna sua ideia de além-do-homem como "o logro do demasiado homem ou do homem e meio"4, acrescentando que o substancial de seu pensamento é a doutrina do domínio e preeminência da aristocracia frente aos valores democráticos e igualitários ${ }^{5}$.

2 Maragall, J., "Nietzsche”, In: L'Avenc, Barcelona, Julho de 1893; Cf. Sobejano, G., op. cit., p. 37.

3 URALES, F., La evolución de la filosofía en España, Barcelona, Ed. Cultura Popular, 1968, p. 181.

4 BECERRO DE BENGOA, R. "Sobre Nietzsche", In: La Ilustración española y americana, Madrid, Fevereiro de 1894. Cf. SOBEJANO, G. "Reflejos de Nietzsche en el mundo hispánico". In: Revista de Occidente de 1973 (125-126), p. 303.

5 É significativa, nesse sentido, a recepção do pensamento de Nietzsche nestes anos por parte do movimento anarquista, que $o$ aceita a partir da perspectiva de um acratismo aristocratizante por sua oposição frontal e sua crítica radical ao Estado como macroestrutura de dominação 
Meca, D. S.

Talvez um dos autores que melhor reflete a atitude do modo de recepção de Nietzsche dentro do movimento regeneracionista é Ramiro de Maeztu quem, em sua época, apareceu como o "nietzschiano mais exaltado", nas palavras de Unamuno. Isto deu origem a exclamações tais como: "que venha o além-do-homem messiânico cujo valor heroico nos mobilize a nos desprender da corcova do passado que nos impede de realizarmos nossos sonhos" ${ }^{\circ}$. No segundo Maeztu já não se percebe esse fervor nietzschiano, mas permanece sua apreciação positiva do espírito de superação, sua valoração da intuição frente ao objetivismo racionalista e a exigência de novos valores, todos juntos com outros elementos já mais polêmicos como a estimação positiva da guerra e um determinado ideal de homem regenerado. Em suma, o que de Nietzsche é considerado por Maeztu é o pensamento estimulante e rendável frente à paralisia e a decadência da Espanha, e assim se pode falar de influência clara da ideia de Nietzsche da vontade de potência na concepção madura que Maeztu desenvolve sobre os valores objetivos ${ }^{7}$. Há também claros vestígios de ideias nietzschianas nas obras e personagens de Pío Baroja, que caracteriza com simpatia Nietzsche de "médico rude e implacável para com os enfermos da vontade"". Ortega assinalou com perspicácia o caráter nietzschiano de Andrés Hurtano, o personagem de $E l$ árbol de la ciência, que é precisamente um médico que sonha com realizações culturais capazes de despertar o esforço da vontade, a força da vida, frente à inercia cinza do objetivismo

opressiva. Cf. GINER DE LOS RÍOS, F. "Nietzsche, fragmentos de un estudio sobre el anarquismo", Madrid, 1916. Cf. Sobejano, G., Nietzsche en España, op. cit., p. 61-62.

6 MAEZTU, R., Hacia otra España, 1899; Cf. SOBEJANO, G., Nietzsche na Espanha, op. cit., p. 57-61 e 318-347.

7 Também Azorín expressa, em geral, uma atitude muito receptiva diante da obra de Nietzsche, e deixa isso patente em seu artigo "La Voluntad" (1902) e em suas Confesiones de un pequeño filósofo (1904).

8 BAROJA, Pío. "Nietzsche y la filosofía". In: Revista Nueva 1899, 15 de Fevereiro e 5 de Agosto. Ver igualmente "Nietzsche íntimo". In: El Imparcial 1901, 9 de Setembro e 7 de Outubro, e "El éxito de Nietzsche". In: El Globo, Dezembro de 1902; Cf. Sobejano, G., Nietzsche na Espanha, op. cit., p. 347-395.

20 I Cad. Nietzsche, São Paulo, v.36 n.1, p. 17-44, 2015. 
científico que promove o abstracionismo da atitude positivista e mecanicista9. Por outro lado, a posição de Antonio Machado frente a Nietzsche foi sempre ambivalente. Mairena não simpatiza abertamente com Nietzsche. Decerto, a Machado interessa o indivíduo, a vida, a estética, o conhecimento intuitivo, o estilo literário e poético, ou seja, tudo o que interessa aos nietzschianos de seu tempo, contudo, há aspectos do pensamento de Nietzsche como a moral aristocrática e suas derivas políticas que não se encaixam com a sua sensibilidade. E quase o mesmo pode ser dito, em parte, de Unamuno, que expressamente insiste no pouco apreço e até na hostilidade para com as ideias nietzschianas, "com o anarquismo transcendental, filosófico e explosivo". Ele diz que "tem contribuído para criar gênios não pouco tolos e que figurem ter alma de leões por terem aprendido seus aforismos... É difícil simpatizar com os nietzschianos, sobretudo com os nascidos em países católicos onde a ignorância sobre a religião é geral"10. Não obstante, quando se lê atenciosamente Unamuno, não é incomum que este autor se mostre muito mais nietzschiano do que ele tencione parecer. Pois aspectos estruturais básicos do seu modo de pensar coincidem com abordagens de Nietzsche, como, por exemplo, em sua crítica à razão moderna e em sua afirmação irracional da vida como vida eterna, separando-lhes só no que Nietzsche conclui desta afirmação desde a crença pagã no eterno retorno e Unamuno desde o dogma cristão da imortalidade. Por último, quanto à presença de Nietzsche em Ortega y Gasset, talvez ainda seja preciso realizar um estudo em profundidade que analise precisamente essa complexa e rica relação. $O$ jovem Ortega se refere a sua leitura da obra de Nietzsche como uma "travessia de uma zona tórrida" cuja temperatura lhe proporciona orgulho e crítica ante a espanhola veneração nacionalista do passado.

9 ORTEGA Y GASSET, J., "Pío Baroja: anatomía de un alma dispersa”, em Obras Completas, ed. Revista de Occidente, Madrid, Vol. IX, p. 491.

10 UNAMUNO, M., "Voltaire, Rousseau, Nietzsche", em Contra esto y aquello (1912); Cf. SOBEJANO, G., Nietzsche na Espanha, op. cit., p. 276-318. 
Meca, D. S.

Nietzsche desperta no primeiro Ortega o entusiasmo pela vitalidade do homem distinto, para quem viver é "mais viver", e para quem a moral é um conjunto de valores que esse homem dá a si mesmo de acordo com seu sentido de liberdade. Este além-do-homem não representa um destino fatídico e imutável, mas o ponto de partida do que se pode ser. Devem-se denunciar as múltiplas e sutis formas de resignação e ressentimento contra si mesmo que minam e anulam a vitalidade e as possibilidades do homem contemporâneo: "o além-do-homem é o sentido do homem porque é a melhoria do homem, e o homem deve ser superado porque ele ainda pode ser melhor"ll. No Ortega maduro, por outro lado, percebe-se igualmente a afirmação nietzschiana da vida frente aos limites da razão moderna, mas, nesse caso, essa afirmação não é irracional como em Unamuno, mas retorna à razão mesma com a intenção de reformá-la em uma razão vital, uma razão capaz de servir a valores vitais, a uma cultura e a uma moral da vida e para a vida.

Entre 1939 e os anos sessenta do século passado, ocorreu um silêncio significativo e olvido do pensamento nietzschiano. Sobejano fala do distanciamento dos jovens intelectuais desta época em relação a Nietzsche e sua preferência maior por Marx, na medida em que, a partir da perspectiva em que Nietzsche foi recebido e interpretado anteriormente, sua influência foi nociva em relação à Guerra Civil e de suas consequências: "a vontade se faz violência, a aristocracia se degenerou em autoritarismo, o individualismo em anarquia fracassada, a glorificação da vida em desespero com respeito ao sentido humano e solidário da vida" ${ }^{2}$. Conquanto não seja possível estabelecer uma relação direta neste sentido, em todo caso é certo que o interesse por Nietzsche somente reaparece na Espanha ao cabo de uma profunda mudança política resultante

11 ORTEGA Y GASSET, J. "Teoría del clasicismo II" (1907); ver igualmente "El sobrehombre" (1908), que é um comentário de Ortega sobre o livro de G. Simmel, Schopenhauer und Nietzsche (1907); Cf. SOBEJANO, G. Nietzsche na Espanha, op. cit., pp. 527-565.

12 SOBEJANO, G. Nietzsche na Espanha, op. cit., p. 664.

22 I Cad. Nietzsche, São Paulo, v.36 n.1, p. 17-44, 2015. 
de uma transição à democracia, consolidada com a integração de nosso país na Comunidade Europeia, e da forte transformação cultural que essa mudança representou. Logo se volatilizaram os últimos resíduos da cultura nacional católica do tardofranquismo e se rompeu decisivamente com o passado filosófico imediato visto como uma etapa de involução tradicionalista. Entre o final dos anos sessenta e início dos anos setenta, uma geração de "jovens filosóficos" começou já a protagonizar esse processo de ruptura a partir de três áreas teóricas bem definidas: o marxismo, a filosofia analítica e o nietzschianismo. Em seguida, a recepção de Nietzsche naquela época é a recepção de Nietzsche dos autores franceses do momento, tais como Deleuze, Foucault, Bataille e Klossowski, cujas obras são as primeiras a serem traduzidas e difundidas. Devido à influência francesa, o interesse é centralizado em questões como a crítica nietzschiana da linguagem, de modo a refutar as doutrinas e sistemas periclitados (Foucault); a afirmação do devir, o jogo, o acaso e o múltiplo como denúncia das forças reativas da dialética, o ressentimento e a má consciência (Deleuze); a exaltação do momento, da sorte, do talvez, da ligeireza e imanência (Bataille); a pulsionalidade do indivíduo que aceita o eterno retorno e a interpretação psicanalítica do pensamento nietzschiano (Klossowski). Em suma, Nietzsche é visto como o pensador que abre espaço a um novo modo de pensar e a uma nova estrutura a partir da qual os significados podem adquirir outros significados. Já não é o Nietzsche enaltecedor da vontade de potência e da exaltação vitalista, como nos tempos de 1898, nem o teórico do além-do-homem e da moral dos senhores, como em torno de 1914. Agora Nietzsche é recebido como um crítico da razão, do cristianismo e da cultura moderna que possibilita uma crítica total a partir de uma atitude de niilismo ativo, o filósofo que faz do filosofar um experimento, o defensor do acaso e afirmador de um devir inocente.

Esse é o horizonte hermenêutico dos artigos que compõem o livro que presumi como ponto de partida do novo interesse em Nietzsche na Espanha: En favor de Nietzsche, publicado em 1972 e com 
Meca, D. S.

a colaboração de Eugenio Trías, Fernando Savater, S. González Noriega, P. Fernández Flórez, A. González García, Javier Echeverría e Ramón Barce. Esses autores, sobretudo Trías e Savater, serão os que com mais impacto desenvolvem um pensamento original com certas ressonâncias nietzschianas. Como Nietzsche, Trías é um escritor cuidadoso e versátil e é significativo que, em 1971, publicou La dispersión, um livro de aforismos de um profundo sabor nietzschiano. Em Drama e identidad (1974) é recorrente a atenção ao "sentido trágico da vida", e mais tarde em sua Lógica del limite (1991), a experiência trágica mostra seu impulso afirmativo e criativo. Também em sua Filosofia del futuro (1983) é oferecida uma versátil interpretação do eterno retorno, e sua ocupação com Nietzsche reaparece em seu artigo "Instante y eternidad (Una aproximación al Así hablo Zaratustra de Nietzsche)" e em seu livro El hilo de la verdad, de 2004, no capítulo intitulado "Las metamorfosis del espíritu". Quanto a Fernando Savater, sua aproximação inicial com Nietzsche esteve muito mais diretamente vinculada a sua atitude crítica característica: "para nós, o essencial de Nietzsche é a blasfêmia... contra as formas de fé de Deus, a identidade pessoal, a razão científica, as lições e o sentido da história, as categorias gramaticais, a compaixão, o autossacrifício, os direitos dos homens, o democratismo humanista"13. O Nietzsche de Savater é o crítico da consciência e da valorização do corpo como realidade expressiva; o instaurador do acaso que rompe os laços da causalidade e propõe a fidelidade ao instante, no esquecimento da memória da própria subjetividade; e o pensador rebelde disposto a pulverizar verdades e sistemas estabelecidos que possam representar algum impedimento à liberdade. Em suas obras posteriores, Invitación a la ética, La tarea del héroe, Ética como amor propio, Idea de Nietzsche etc., esse impulso nietzschiano de golpear as estruturas sociais e

13 SAVATER, F. Inventario, Madrid, Taurus, 1973, Prólogo; outros trabalhos de Savater: Nihilismo y acción, Madrid, Taurus, 1971; Conocer Nietzsche y su obra, Barcelona: Dopesa, 1979; Idea de Nietzsche, Barcelona: Ariel, 2000.

24 I Cad. Nietzsche, São Paulo, v.36 n.1, p. 17-44, 2015. 
ideológicas para despojá-las de suas anuências caducas e esclerosadas pode ser percebido junto ao propósito de promover os valores que permitem ao indivíduo ser fiel a suas convicções e princípios ${ }^{14}$.

\section{Os últimos trinta anos.}

Em todo caso, a partir dos anos oitenta se esboça, de maneira cada vez mais firme, o interesse pelo pensamento de Nietzsche em seus aspectos mais propriamente filosóficos. É significativo que, ao contrário do que aconteceu em outros âmbitos geográficos, na Espanha não foram os especialistas em ética ou em estética que se detiveram mais em Nietzsche, mas os historiadores da filosofia e, sobretudo, os metafísicos. $\mathrm{O}$ autor mais determinante para a interpretação de Nietzsche foi Heidegger, no entanto os novos intérpretes não se limitaram simplesmente a parafrasear sua exegese. Mas foi a partir da topologia metafísica dessa recepção que doravante se interpretaram e analisaram os problemas éticos, estéticos e políticos. Exemplos eloquentes disso são as obras que foram publicadas nos anos oitenta. Assim, na monografia de Juan Luis Vermal, La crítica de la metafísica en Nietzsche ${ }^{15}$, se aborda o diálogo ou controvérsia entre Nietzsche e Heidegger, na convicção de que apresentam caminhos decisivos e alternativos ante uma crise da metafísica

14 Em 1971, Luis Jiménez Moreno publica sua obra El pensamiento de Nietzsche (Labor, Barcelona), que se propõe a apresentação da figura de Nietzsche à margem de partidarismos e utilizações, isto é, doravante o propósito de leitura em chave filosófica. Dessarte, no solo da filosofia de Nietzsche, mas também de sua formação e de suas consequências. Para Jiménez Moreno, Nietzsche é um vitalista que se opõe com força a todo idealismo e que se concentra no problema da vida como vida humana. No mesmo sentido: El pensamiento de Nietzsche, Madrid: Cincel, 1984.

15 VERMAL, J.L. La crítica de la metafísica en Nietzsche. Barcelona: Anthropos, 1987. Vermal tem prosseguido esse estudo em trabalhos posteriores, tais como "Acerca de la superación nietzscheana de la metafísica". In: Nietzsche actual e inatual. Buenos Aires: 1994; "Nietzsche, el último metafísico". In: Revista de Occidente, 226 (2000). "¿Quién es el Nietzsche de Heidegger?". In: Estudios Nietzsche, 1 (2001). 
Meca, D. S.

que é central e determinante para nossa época. Apesar de admitir, na contramão do que costuma se aceitar atualmente, a pertinência da leitura heideggeriana de Nietzsche, a possibilidade desse diálogo ou controvérsia exige, para Vermal, uma leitura deste último que exceda os limites nos quais é reduzido na interpretação de Heidegger. Desse modo, poderiam ficar desenhadas as possibilidades históricas essenciais que se abrem, em nossa época, entre uma possível assunção de uma força configuradora ("vontade de potência"), mais além de seus encerramentos metafísicos, ou a necessidade de um "passo atrás" que requer antes de tudo uma posição de escuta. O livro de Julio Quesada, Un pensamiento intempestivo: Ontología, estética y política en Nietzsche ${ }^{16}$, ainda que se centre nos escritos de juventude, também se refere ao último Nietzsche com a intenção de reavaliar as conclusões extraídas com respeito às primeiras obras. Trata-se de estabelecer a conexão entre ontologia, estética e política, tomando como fio condutor a noção de intempestividade com respeito tanto ao nazismo como à metafísica platônico-cristã. A crítica de Nietzsche inverte certas categorias ontológicas, especialmente a de finalidade, da qual depende diretamente o entendimento da relação entre indivíduo, Estado e história. Traçado assim o contexto, Quesada adota como modelo a capacidade criadora do artista para engendrar a noção de "unicidade produtiva" e a partir dela definir o conceito de individualidade como noção ético-política, distinta do conceito metafísico de sujeito, que entrecruzam e harmonizam pluralidade e singularidade. Essa individualidade e sua capacidade de transformação criadora da physis (que não é dominação técnica nem negação ascética) a partir do rendimento axiológico da cultura constitui o fundamento - diz Quesada - ao mesmo tempo intempestivo e ilustrado do pensamento de Nietzsche, frente aos diferentes poderes niilistas que preconizam a desindividuação metafísica da

16 QUESADA, J. Un pensamiento intempestivo: Ontología, estética y política en Nietzsche, Barcelona: Anthropos, 1988.

26 I Cad. Nietzsche, São Paulo, v.36 n.1, p. 17-44, 2015. 
identidade ou o monoteísmo do Estado totalitário. Ao mesmo tempo se resgata a noção kantiana de "finalidade sem fim" para aplicar à estrutura do devir, em uma espécie de radicalização ontológica do julgamento reflexivo kantiano, junto com a função produtiva e criadora própria da imaginação no jogo das faculdades do espírito, com o fim de interpretar a ideia do eterno retorno como devir aberto das diferenças e da pluralidade, sem que tal devir aponte para nenhum fim objetivo, transcendente ou imanente ${ }^{17}$.

Dentro desse mesmo horizonte, outros autores adotam com preferência o motivo do pensamento trágico para apresentar novas propostas e saídas do círculo de noções e relações em que as ideias de Nietzsche estão sob o domínio da interpretação heideggeriana. Assim, por exemplo, o livro de Remedios Ávila, Nietzsche y la redención del $a z a r^{18}$, propõe-se a estudar a progressiva configuração, em Nietzsche, de uma ética trágica e, para isso, começa, em sua primeira parte, clarificando o sentido do trágico, opondo-o tanto ao otimismo socrático do homem de ciência como ao pessimismo estético schopenhaueriano. $\mathrm{O}$ trágico nietzschiano é para a autora um pathos afirmativo em relação com a totalidade da vida, incluindo seus aspectos mais terríveis e dolorosos. A tragédia, como obra de arte, oferece assim um modelo ontológico do mundo e da existência que aponta a sua possível transformação a partir de uma aposta trágica por meio desse pathos afirmativo. Na segunda parte, é analisada a crítica nietzschiana à cultura tal como se realiza nas obras do período intermediário, valorizando a aplicação da genealogia nietzschiana aos sistemas de valores da cultura contemporânea que os desvela pela exiguidade de fundamento metafísico, tanto no que se refere à origem da moral como relativa, como no que diz

17 Outros trabalhos em que Quesada desenvolve suas propostas iniciais e evolui para outros horizontes são: El Nihilismo activo. Genealogía de la Modernidad. México: Universidad de Guadalajara, 1999; La Belleza y los humillados, Barcelona: Ariel, 2001, além de uma grande quantidade de artigos.

18 ÁVILA, R. Nietzsche y la redención del azar. Granada: Universidad de Granada, 1987. 
Meca, D. S.

respeito às construções desenhadas pela vontade de potência. $\mathrm{O}$ que não significa, no entanto, a renúncia a todo projeto ético alternativo. Por último, na terceira parte, Remedios Ávila expõe esse projeto ético mergulhando no "imoralismo" de Zaratustra, baseado na aceitação da "morte de Deus" (solidão metafísica do indivíduo como condição trágica de sua liberdade e responsabilidade), no entendimento do mundo como vontade de potência e na aceitação do eterno retorno como redenção da temporalidade. Desse modo, é a noção de além-do-homem a que encarna esse desenvolvimento das forças ativas e essa redenção do acaso, atribuindo um sentido intramundano ao domínio do absurdo, e especificando em sua figura a aposta trágica cuja máxima seria ludere aude. Remedios Ávila continuou posteriormente desenvolvendo essa perspectiva do pensamento trágico, adotada em sua primeira monografia, para aplicá-la, concretamente, ao tema da identidade do sujeito na situação de fragmentação e crise em que o afunda a modernidade. É a temática de seu livro Identidad y tragedia: Nietzsche y la fragmentación del sujeto $^{19}$. Partindo de uma detalhada contextualização do problema na contraposição ilustração/romantismo, e matizando a análise com propostas sobre novas formas possíveis de entender a filosofia (como exercício de desilusão e desengano, como busca da saúde etc.) conclui por reformular a noção de identidade desde a ótica da arte e a ideia de individualidade como "estilo de caráter". Por último, em seu livro El desafio del nihilismo ${ }^{20}$, Remedios Ávila propõe uma revisão do significado de niilismo retomando a pergunta pela possibilidade de superá-lo, mas estabelecendo como ponto de vista distinto de sua explicação a metafísica e o que esta poderia

19 ÁVILA, R. Identidad y tragedia: Nietzsche y la fragmentación del sujet. Barcelona: Crítica, 1999.

20 ÁVILA, R. El desafío del nihilismo. Madrid: Trotta, 2005. Outros trabalhos dessa autora, que enriquecem sua dedicação ao estudo da obra de Nietzsche, são: "Heidegger y el problema de la nada. La crítica a la posición de Nietzsche". In: Pensamiento. Vol. 63 (2007), n. 235; "La crítica de Nietzsche al Romanticismo". In: Estudios Nietzsche. Revista de la Sociedad Española de Estudios sobre F. Nietzsche. Número 5 (2005).

28 I Cad. Nietzsche, São Paulo, v.36 n.1, p. 17-44, 2015. 
opor ao desafio que o niilismo supõe. A autora visa neste sentido à antiga noção grega de pietas com respeito à vida, referida, sobretudo, a sua complementaridade com o agonismo em que tal noção se configura no marco da tragédia clássica. $\mathrm{O}$ que talvez chame mais atenção nesse livro é a sua sensibilidade para as tendências e problemas de nossa cultura contemporânea, jogando luz sobre elas a partir da grande questão da crise da metafísica ou desde um uso sugestivo da ideia de duplo, ou vindicando uma revisão da condenação nietzschiana da figura de Sócrates, ou repensando o problema da compaixão.

Também os livros de Manuel Barrios adotam como ponto de partida a noção de pensamento trágico para diversificar as possibilidades e objetivos de seu interesse central na relação entre Nietzsche e o romantismo. Em La voluntad de poder como amor ${ }^{21}$, o autor se propõe a confrontar a definição que faz Heidegger da vontade de potência como vontade de domínio técnico do mundo por parte de uma razão calculadora, manipuladora e exploradora, para, apoiando-se em textos nietzschianos, sobretudo da época de Zaratustra, perfilar uma caracterização diferente da vontade de potência em que se entrelaçam amor, criatividade, superação e ocaso como desejo de retorno. Já anteriormente, e para superar o pessimismo metafísico e moral de Schopenhauer, o jovem Nietzsche sublinhava no conceito de vontade a força exuberante da natureza em seu inocente prazer trágico que cria e destrói sem cessar os mundos. Mas é em Zaratustra que essa ideia se explicita e se desenvolve a partir de metáforas como a do Sol, que dissipa sua luz dourada e sua potência revitalizadora em uma espécie de generosidade prometeica e de amor

21 BARRIOS, M. La voluntad de poder como amor. Barcelona: Serbal, 1990 (2a edição em Arena Libros, 2006, com um prólogo de Eugenio Trías). Cf. também Hölderlin y Nietzsche: Dos paradigmas intempestivos de la modernidad en contacto. Sevilla: Universidad de Sevilla, 1992; Voluntad de lo Trágico: el concepto nietzscheano de voluntad. Madrid: Biblioteca Nueva, 2002; “¿Expulsar de Nuevo al Poeta? de Arte y Política en Nietzsche”, In: Estudios Nietzsche 2007 (7), 11-36; "Nietzsche y el Retorno Romántico a la Naturaleza", In: Estudios Nietzsche 2005 (5), 33-66. 
para com os homens. Essa metáfora do Sol, que Nietzsche toma de Hölderlin, identifica assim a vontade de potência como uma super-plenitude que quer transbordar, e que não se contenta com presentear os dons de sua riqueza senão com o desejo de transcender na criação de algo que esteja acima se si (o além-do-homem). Por isso, como flecha de anseio para outra margem, essa vontade deve ser, ao mesmo tempo, vontade de ocaso (Untergang), felicidade de autossacrifício como prelúdio de um novo nascimento e uma nova aurora em um retorno do mesmo sem fim. Narrar el abismo. Ensayos sobre Nietzsche, Hölderlin y la disolución del classicismo ${ }^{22}$ recolhe vários trabalhos de feitura diversa, mas que conseguem mostrar, em seu conjunto e classificação, uma problemática de fundo interessante por sua atualidade e muito atrativa por seu conteúdo mesmo. Na introdução, Barrios confessa que sua intenção é "conferir forma filosófica, narrativa - e em última instância histórica - à experiência de dissolução do mundo moderno, apelando aos dois autores que em outros livros anteriores me serviram de guia e estímulo: Hölderlin e Nietzsche". E o que os capítulos do livro fazem é ir despregando os contextos, as interrogações e o conjunto de análise que, partindo da compreensão de nossa época como a do descobrimento da fragmentação de nossa existência, preparam-se para debater e configurar aqueles elementos histórico-hermenêuticos com os quais torne possível recriar efeitos de sentido sem já pressupor referentes dogmáticos e metafísicos.

A tese do livro de Diego Sánchez Meca En torno al Superhombre: Nietzsche y la crisis de la modernidade ${ }^{23}$ se desenvolve num fio de uma análise de confrontação que Nietzsche leva a cabo, ao longo de toda sua obra, entre arte e ciência. O propósito dessa confrontação é

22 BARRIOS, M. Narrar el Abismo: Ensayos sobre Nietzsche, Hölderlin y la disolución del clasicismo, Valencia: pré-textos, 2001.

23 SÁNCHEZ MECA, D. En torno al superhombre: Nietzsche y la crisis de la modernidad. Barcelona: Anthropos, 1989; Cf. Também “¿Quién es el superhombre de Nietzsche? El juego de las adivinanzas", In: SÁNCHEZ MECA, D. Metamorfosis y confines de la individualidad. Madrid: Tecnos, 1995, p. 137-198. 
fazer ver a distância que ainda separa o humano, demasiado humano, ou seja, ao expoente ao mesmo tempo em que resulta da razão moderna, com respeito à ideia reguladora do além-do-homem. Além disso, isso mostra uma importante dependência que Nietzsche tem de Goethe e do primeiro romantismo alemão, e essa conexão é o que examina a primeira parte do livro, que conclui com a afirmação de uma significativa diferença: enquanto nas formas de arte a criação se produz livremente, sem coação, ou seja, de um modo aberto ao imaginativo, ao fictício e ao gratuito, na ciência, tal como é concebida na época moderna, o conhecimento se produz como hybris, ou seja, como violência delimitadora e redutora de diferenças. E neste contexto, a ótica da arte permite antecipar o que representaria a libertação da criatividade cognitiva de toda limitação imposta pela exigência de objetivação e da necessidade de se subordinar a uma técnica. Isto é, além da preocupação pela objetividade, pela certeza, pelo consenso, pela segurança, qualidades todas elas ao serviço de um melhor domínio de situações e de outros homens, o conhecimento dionisíaco, próprio do além-do-homem, seria aquele que não está determinado já por uma vontade de segurança, senão por uma vontade de experimentação e de aventura. De modo que, em lugar de uma busca de verdades universais e necessárias, o conhecimento seria sinônimo de doação de nomes as coisas, exercício de libertação como movimento da interpretação. Assim, o über do Übermensch não aluiria nem ao traspassamento de uns impulsos ou instintos na luta pela sobrevivência, nem tampouco a uma vontade que se desdobra no domínio científico e técnico do mundo (como crê Heidegger), senão que simplesmente viria a explicitar a estrutura característica da experiência hermenêutica como caminho ascendente. Em Nietzsche: La experiencia dionisíaca del mundo ${ }^{24}$, trata-se de estruturar o problema concreto do diagnóstico do estado fisiopsicológico do homem

24 SÁNCHEZ MECA, D. Nietzsche: la experiencia dionisíaca del mundo. Madrid: Taurus, 2005 ( $3^{\circ}$ edição 2008). 
Meca, D. S.

europeu e da evolução de sua cultura. A primeira parte ocupa-se do contraste entre a interpretação juvenil nietzschiana da cultura grega e a arte de Wagner, discussão sustentada em toda da produção primeira do jovem Nietzsche a partir da questão metafísica da existência como dor que o despertara a leitura de Schopenhauer. A segunda parte baseia-se nessa inicial fisiologia dos instintos artísticos, apolíneo e dionisíaco - que se desenvolve em $O$ nascimento da tragédia e que Nietzsche utiliza como paradigma hermenêutico em sua interpretação da cultura grega -, e o reelabora como modelo da força agonística e artisticamente plasmadora dos instintos como chave para entender a relação do corpo e da cultura. Estabelecida essa relação, e delimitados os critérios de uma cultura sã frente à outra decadente, Sánchez Meca vai examinando as diferentes formas e tendências que Nietzsche considera doentes na cultura europeia moderna: o Estado democrático e sua política social, o gregarismo, o feminismo, a mitificação do trabalho e do conforto, a violência, a compaixão com os débeis e marginados etc. O livro acaba com três capítulos em que se discutem três grandes interpretações do pensamento de Nietzsche: a de Heidegger, a de Habermas e a de Deleuze. Também El nihilismo: perspectivas sobre la historia espiritual de Europa ${ }^{25}$ consta de três partes unidas por um fio condutor. Desde a ótica de Nietzsche, entende-se o progresso do niilismo, que percorre a história do Ocidente, como a repetição querida, aceitada e lograda da decadência. Isto é, entende-se o niilismo como a interiorização do encadeamento histórico dos diferentes momentos em que a vontade de potência nega a si mesma. Esquema explicativo,

25 SÁNCHEZ MECA, D. El nihilismo: perspectivas sobre la historia espiritual de Europa. Madrid: Síntesis, 2004. Outros escritos recentes de Sánchez Meca são: "Voluntad de poder e interpretación como supuestos de todo proceso orgánico". In: Estudios Nietzsche 2009 (9), pp.105-122; "Nietzsche y la idea romántica de una nueva mitología". In Estudios Nietzsche 2005 (5), p. 129-152; "Razones de la moral y exigencias de la vida: Kant contra Nietzsche", In: Daimon. Revista de Filosofía, 2004 (33), p. 157-166; "Généalogie et critique de la philologie aux sources de Choses humaines. trop humaines", In: D’Iorio, P.-Ponton, O. (eds.), Nietzsche. Philosophie de l'esprit libre, Paris, Editions rue d'Ulm, 2004, pp.79-98. 
portanto, que articula uma filosofia da história nas antípodas do pensamento hegeliano, já que o cume final do progresso aqui não é a síntese totalizadora, mas o esquecimento de seu próprio percurso.

Outros autores estendem o âmbito de seus interesses e estudos a uma grande variedade de temáticas e de implicações da figura de Nietzsche ou de seu pensamento. Tal é o caso de Joan B. Llinares, grande conhecedor da obra de Nietzsche e de seu contexto, cujos trabalhos merecem uma especial menção por seu rigor, erudição e grande acerto exegético na diversidade do tratado: a linguagem, a ciência, o ceticismo, o trágico, a dialética do senhor e do escravo, a figura de Sócrates, as relações de Nietzsche com Wagner e com Brahms, Nietzsche e Dostoiévski, a influência sobre G. Benn, a sexualidade, o teatro, a guerra, a mulher etc. ${ }^{26}$ Quanto aos escritos de Jesús Conill, a perspectiva e o enfoque adotados são os provocados pela peculiar forma do pensamento e do estilo de Nietzsche, seguindo os novos impulsos e orientações da investigação internacional. Os aspectos que mais têm atraído sua atenção são: em El crepúsculo de la metafísica ${ }^{27}$, a crítica radical das tradições metafísicas do pensamento e de sua profundidade moral; em $E l$ enigma del animal fantástico ${ }^{28}$, a concepção do homem como animal fantástico e suas consequências nos diversos âmbitos da vida humana; em El poder de la mentira. Nietzsche y la política de la transvaloración ${ }^{29}$, a crítica dos valores e das instituições modernas

26 LLINARES CHOVER, J.B. Hombre, arte y lenguaje. Una investigación sobre el joven Nietzsche. Servei de Publicacions de la Universitat de València: 1982; "Nietzsche y el escepticismo. Ensayo aclaratorio de una pretendida contradicción”. In: Mirar con cuidado (J. Marrades y N. Sánchez, eds.), Valencia: pré-textos, 1994; "Nietzsche en los ensayos del poeta Gottfried Benn. Una aproximación”. In: Nietzsche, 100 años después (ed. J. B. Llinares), Valencia: Pre-textos, 2002; "El teatro y la mujer en los escritos de F. Nietzsche sobre R. Wagner". In: L'ordim de la llar, Bari, Levante, 2003; "Consideraciones sobre la guerra en Nietzsche". In: La guerra (Edición de Nicolás Sánchez), Valencia: Pre-textos, 2006.

27 CONILL, J. El crepúsculo de la metafísica. Barcelona: Anthropos, 1988.

28 Idem. El enigma del animal fantástico. Madrid: Tecnos, 1991.

29 Idem. El poder de la mentira. Nietzsche y la política de la transvaloración. Madrid: Tecnos, 1997 (1 ${ }^{\mathrm{a}}$ ed.), com Prólogo de Pedro Laín Entralgo; 2001 (2 ed.), com Epílogo: "Orientación nietzscheana de nuestra tradición filosófica". 
Meca, D. S.

(por exemplo, a democracia), a partir da transvaloração e da grande política; e em outros trabalhos, a metáfora do além-do-homem; a transformação da crítica kantiana em hermenêutica genealógica, como crítica da razão impura, e portanto, a relação de Nietzsche com a hermenêutica contemporânea; a orientação nietzschiana do pensamento espanhol contemporâneo (Unamuno, Ortega, Zubiri, Laín...); e a radicação poética do pensamento e da vida humana ${ }^{30}$. $\mathrm{O}$ que considera que este pensamento tem vigência e atualidade para nosso mundo e nossa sociedade espanhola, em concreto, é o estilo de pensamento vivo, aberto às diversas ciências, mas sem dogmatizá-las, e que toca os aspectos cruciais da vida moderna padronizada, urgindo a repensar seus pressupostos quebradiços.

Luis Enrique de Santiago Guervós se interessou, antes de tudo, pela questão da linguagem e pelos problemas que Nietzsche propõe inicialmente à ciência filológica. Daí sua edição dos textos de Rohde, Wagner e Wilamowitz, que surgiram sob a raiz da polêmica filológica que se originou em torno da publicação de $O$ nascimento da tragédia, em cuja introdução insiste na relação entre a interpretação e a concepção da arte própria do jovem Nietzsche. Este é o tema desenvolvido em Arte y poder. Aproximación a la estética de F. Nietzsche $e^{31}$, na qual expõe o percurso que a reflexão sobre a arte tem na obra de Nietzsche, desde a juvenil e schopenhaueriana "metafísica de artista" até a última e genealógica "fisiologia da arte". O objetivo é determinar em que sentido a arte pode ser proposta como o problema filosófico fundamental ao ser manifestação de um poder (Macht) de criar aparências, de configurar significados e interpretações com os quais se faz do caos um mundo de formas, e que é o mesmo poder da força (Kraft) criadora universal da natureza e da essência da linguagem e do conhecimento. A partir

30 Cf. em concreto, CONILL, J. "Recuperación postnihilista del individuo y la realidad: la metáfora del superhombre", Valencia: Quaderns de Filosofía y Ciencia, 1991, p. 7-17.

31 SANTIAGO, Luis de. Arte y poder. Aproximación a la estética de Nietzsche. Madrid: Trotta, 2004.

34 I Cad. Nietzsche, São Paulo, v.36 n.1, p. 17-44, 2015. 
dessa hipótese não é difícil imaginar as questões que se abrem; por exemplo, que tipo de crítica representa a arte como "ficção" a respeito do conceito filosófico-metafísico e científico de "verdade"; ou qual é a relação existente entre o ato de criação artística com a saúde e a doença, relação decisiva se a toma - como queria Nietzsche - como critério para julgar a decadência e propor a possível superação do niilismo da cultura ocidental. Em tal caso, uma revolução estética seria a chave de tal superação. Pois enquanto a arte nascida da saúde atua como sugestão sobre os sentidos, tonifica e aumenta o prazer e a vontade de viver mediante sua glorificação do sensível, toda a arte decadente moderna não é mais que um exagero não clássico, histérica e vulgar dos traços principais, das grandes linhas e dos efeitos histriônicos que ocultam uma intenção secretamente tirânica: a da manipulação dos nervos enfermos por meios terroristas. Como a moral ou a metafísica niilistas, a arte moderna também recorre à violência como forma habitual de exercer o poder sobre um rebanho de indivíduos débeis e atormentados ${ }^{32}$.

A partir de todos esses trabalhos pode ser verificada a recepção e reelaboração de uma imagem nova e diversamente matizada dos conceitos nietzschianos de vontade de potência, além-do-homem, eterno retorno, o trágico, o dionisíaco, a interpretação, a arte etc., bem distinta, em qualquer caso, tanto dos centros de gravidade da primeira recepção espanhola de Nietzsche, como das posteriores projeções sociais e políticas desses conceitos de caráter darwinista ou tecnocrático que predominaram em outras zonas geográficas da Europa. Aberto às correntes mais vivas da interpretação internacional, os estudiosos espanhóis têm dirigido sua atenção ao Nietzsche

32 Outros trabalhos de Luis de Santiago são: "Nietzsche y los ideales estéticos del Sur: la necesidad de mediterraneizar la música". In: Analecta Malacitana, no 23/1, 2000, p. 131-148; "Metáfora versus concepto. La generalización de la metáfora en F. Nietzsche". In: Estudios filosóficos 49 (2000), p. 261-275; "La risa y el 'consuelo intramundano': el arte de trascenderse y superarse en Nietzsche”. In: Estudios Nietzsche 1 (2001), p. 145-168; “Cosima Wagner y F. Nietzsche: claves para la interpretación de una relación enigmática. Correspondencia”. In: Estudios Nietzsche 7 (2007). Madrid: Trotta, p. 155-202. 
Meca, D. S.

crítico da filosofia ocidental, do cristianismo e da cultura moderna, mas também e, sobretudo, ao Nietzsche que abre a possibilidade de um novo começo para o pensar contemporâneo; a seu original estilo de escrita; às fontes científicas de seu pensamento, a sua atitude para com as mulheres, ao alcance ético ou político de suas propostas etc. E essa é a linha que prosseguem os estudiosos da geração mais jovem, que dirigem também seu interesse ao estudo desse pensador. Assim, Elvira Burgos, depois de publicar a monografia Dioniso en la filosofía del joven Nietzsche ${ }^{33}$ e de ocupar-se no estudo da crítica nietzschiana ao Cristianismo e na figura de Jesus, em um conjunto posterior de trabalhos analisa a obra de Nietzsche a partir de uma perspectiva feminista, e propõe como as figuras de mulheres em Nietzsche e suas concepções do feminino têm um alcance filosófico relevante que obriga a revisar o suposto antifeminismo e misoginia desse autor ${ }^{34}$. Conclui defendendo em Nietzsche um modo inovador de compreender a categoria "mulher" que clarifica seu modo de fazer filosofia. Para esta autora, o texto de Nietzsche, ao mesmo tempo em que inaugura uma prática filosófica distinta à metafísica dogmática e cristã, possibilita abrir o feminismo em uma nova direção não dogmática. Marco Parmeggiani, em seus livros sobre Nietzsche ${ }^{35}$, reflete sobre o tema da natureza e a possibilidade do conhecimento humano na obra nietzschiana, concentrando em sua teoria perspectivista do conhecimento para se perguntar o

33 BURGOS, E. Dioniso en la filosofía de joven Nietzsche. Zaragoza: Prensas Universitarias de Zaragoza, 1993.

34 Cf. BURGOS, E. "Mujer. Mujeres. Figuras polisémicas en la escritura de Nietzsche". In; Joan B. Llinares (ed.), Nietzsche, 100 años después. Valencia: Pre-Textos, 2002, p. 89112; "Afirmando las diferencias. El feminismo de Nietzsche". In: Asparkía. Investigació Feminista, no 11, 2000, p. 77-93; “A propósito de la misoginia de Nietzsche”. In: Laguna. Revista de Filosofía, no 10, 2002, pp. 133-153; "La cuestión del sujeto. Nietzsche y Butler". In: Fina Birulés y María Isabel Peña Aguado (eds.). La passió per la llibertat, Universitat de Barcelona, 2004.

35 PARMEGGIANI, M. Perspectivismo y subjetividad en Nietzsche. Málaga: Univ. de Málaga, 2002; Nietzsche: Crítica y proyecto desde el Nihilismo. Málaga: Ágora, 2002; Cf. também "Interpretación y textualidad en la aproximación de Heidegger a Nietzsche". In: S. Barbera R. Müller-Buck (eds.), Nietzsche nach dem ersten Weltkrieg, Pisa: Edizioni ETS, 2007. 
que pode contribuir Nietzsche à elaboração de uma teoria hermenêutica na atualidade. Também se destacam as duas monografias de Agustín Izquierdo, dedicadas principalmente à filosofia prática de Nietzsche ${ }^{36}$, assim como os estudos de José Emilio Esteban Enguita $^{37}$ que se interessa por sua vertente política. E assim poderíamos continuar com mais estudos como os de Enrique Lynch $^{38}$, David Pujante ${ }^{39}$, Germán Cano ${ }^{40}$, Hector J. Pérez ${ }^{41}$, José M. Romer Cuevas $^{42}$, E. Ruiz Callejón ${ }^{43}$, entre outros.

\section{Traduções e edições.}

Conta Gonzalo Sobejano que, em 1908, se tinham traduzido já ao castelhano as obras mais representativas de Nietzsche, com exceção das Considerações Extemporâneas, em número de trinta versões em Madri, Barcelona e Valência, pois Nietzsche era bastante comentado e discutido em revistas, jornais e nas tribunas do Ateneu e de algumas Academias. No entanto, a opinião de tais traduções não é absolutamente boa:

36 IZQUIERDO, A. El resplandor de la apariencia: el concepto de cultura en Nietzsche. Madrid: Libertarias Produfi, 1993; Friedrich Nietzsche o el experimento de la vida. Madrid: Edaf, 2001.

37 ESTEBAN ENGUITA, J.E. Política y cultura en el pensamiento del joven Nietzsche (18691876), Universidad Autónoma de Madrid, 1999; Política, historia y verdad en la obra de F. Nietzsche, Universidad de Burgos-Huerga \& Fierro, 2000; "Ecrasez l'infâme!". Cristianismo e historia en Nietzsche". In: Estudios Nietzsche $\mathrm{N}^{\circ} .6,2006,9-26$; "El aristocratismo político de Nietzsche". In: Cuaderno gris, No. 5, 2001, 183-202.

38 LYNCH, E. Dioniso dormido sobre un tigre: A través de Nietzsche y su filosofía del lenguaje. Barcelona: Destino, 1993.

39 PUJANTE, D. Un vino generoso: sobre la estética nietzschiana. Murcia: Universidad de Murcia, 1997.

40 CANO, G. Como un ángel frío. Nietzsche y el cuidado de la libertad. Valencia: Pretextos, 2000; Nietzsche y la crítica de la modernidad. Madrid: Biblioteca Nueva, 2001.

41 PÉREZ, Héctor J. Hacia el nacimiento de la tragédia. Murcia: Res Publica, 2001; Nietzsche y la política. Murcia: Res Publica, 2001.

42 ROMERO CUEVAS, J.M. El caos y las forma. Granada: Comares, 2001.

43 RUIZ CALLEJÓN, E. Nietzsche y la filosofía prática. Granada: Universidad de Granada, 2004. 
Meca, D. S.

executadas muitas delas através do Francês por publicitários de baixa ou nula competência filosófica e literária, retiradas à luz em sua maioria por editoras mais vulgares que informativas, sujeitas a impressão negligente e reimpressões disfarçadas, estragadas pela incúria tipográfica, os erros errantes, a exiguidade ou falta de notas... impossível ao bom trabalhador aduzir um texto de Nietzsche se não era deixado em alemão ou propondo versão própria ${ }^{44}$.

Ainda que não seja extremamente deficiente, tampouco é aceitável a edição de Eduardo Ovejero y Maury, publicada em 1925 em Buenos Aires sob o pomposo e falso título de Obras Completas, que aparentemente segue o texto da alemã Grossoktavausgabe. É uma edição defeituosa basicamente pelo seccionamento arbitrário de um grande número de fragmentos, pela inexata reprodução da numeração original dos aforismos e por contínuos descuidos e erros no deciframento dos manuscritos registrados na mesma edição alemã que lhe serviu de base. Esta e outras que ainda a reproduzem em forma de seleção carecem dos critérios filológicos elementares e têm sido feitas sem pretensão alguma de rigor.

Nos últimos decênios, publicaram-se, tanto na Espanha como na América Hispânica, várias traduções das obras de Nietzsche de qualidade e de valor muito heterogêneos. Destacam, entre elas, a de Escritos sobre retórica (ed. de Luis de Santiago Guervós) ${ }^{45}$, Escritos sobre Wagner (ed. de Joan B. Llinares) ${ }^{46}$, Humano, demasiado humano (ed. de M. Barrios e A. Brotons) ${ }^{47}$, El culto griego a los dioses (ed. de Diego Sánchez Meca) ${ }^{48}$, Sobre verdad y mentira en sentido extramoral y Segunda consideración intempestiva (ed. de

44 SOBEJANO, G., "Sobre la recuperación de Nietzsche”. In: Revista de Occidente, 1973

(125-126), p. 244.

45 NIETZSCHE. Escritos sobre retórica. Madrid: Trotta, 2000.

46 Idem. Escritos sobre Wagner. Madrid: Biblioteca Nueva, 2003.

47 Idem. Humano, demasiado humano. Madrid: Akal, 1996, 2 vols.

48 Idem. O culto grego aos deuses. Madrid: Alderabán, 1999.

38 | Cad. Nietzsche, São Paulo, v.36 n.1, p. 17-44, 2015. 
Joan B. Llinares) $)^{49}$, Schopenhauer como educador (ed. J. Muñoz) $)^{50}$ ou as traduções de Germán Cano de Aurora y La ciencia jovial ${ }^{51}$, para citar só alguns exemplos.

No ano 2000 fundou-se a Sociedade Espanhola de Estudos sobre Nietsche (SEDEN) (www.uma.es/nietzsche-seden), para servir de suporte à investigação sobre Nietzsche entre os filósofos espanhóis. SEDEN publica anualmente a revista Estudios Nietsche (www.estudiosnietzsche.org), em que além de temas de caráter monográfico informa a atualidade bibliográfica, proporciona materiais para a investigação, resenhas e notícias internacionais sobre eventos nietzschianos. E no marco desta Sociedade, e sob a direção de Diego Sánchez Meca, um grupo de estudiosos tem levado a cabo já a edição completa em castelhano dos Fragmentos póstumos de Nietzsche, em quatro grandes volumes: Volume I: Fragmentos Póstumos (1869-1874), tradução, introdução e notas de Luis E. de Santiago, Madrid, Tecnos, 2007 (2 $2^{\text {a }}$ ed. 2010); Volume II: Fragmentos Póstumos (1875-1882), tradução, introdução e notas de Manuel Barrios e Jaime Aspiunza, Madrid, Tecnos 2008; Volume III: Fragmentos Póstumos (1882-1885), tradução, introdução e notas de Jesús Conill e Diego Sánchez Meca, Madrid, Tecnos 2010; Volume IV: Fragmentos Póstumos (1885-1889), tradução, introdução e notas de Joan B. Llinares e Juan L. Vermal, Tecnos, 2006 ( ${ }^{\text {a }}$ edición 2008). Esta mesma equipe continua este labor em uma edição também com outros quatro grandes volumes das Obras completas de Nietzsche, cujo volume I: Escritos de juventud tem prevista sua publicação dentro deste ano de 2010 pela Editorial Tecnos. Também, e sob a direção de Luis de Santiago, se está levando a cabo a edição da Correspondencia em seis volumes, dos quais quatro volumes já publicados entre 2005 e 2010.

49 In: Llinares, J.B.-Meléndez, G. (eds.). Nietzsche: Antología. Barcelona: Península, 1988.

50 NIETZSCHE. Schopenhauer como educador. Madrid: Biblioteca Nueva, 2000.

51 Idem. Aurora. Madrid: Biblioteca Nueva, 2000. La ciencia jovial. Madrid: Biblioteca Nueva, 2001. 


\begin{abstract}
The article analyses the reception of Nietzsche's thought in Spain in the last forty years, showing the several ways by which the philosopher's work was read and the many influences that he carried out, such as in politics, in aesthetics and in the arts. In a first moment, the analysis presents many authors that read Nietzsche and shows how in each moment the philosopher's ideas were invoked in search of renewal, whether moral, aesthetic or politic. In a second moment, it brings into light the academic studies and the diversity of subjects form the nietzschean philosophy considered in them.
\end{abstract}

Keywords: reception - Nietzsche - Spain - interpretation

\title{
referências bibliográficas
}

ÁVILA, R., Nietzsche y la redención del azar. Granada: Universidad de Granada, 1987.

- Identidad y tragedia: Nietzsche y la fragmentación del sujeto. Barcelona: Crítica, 1999.

. El desafío del nihilismo. Madrid: Trotta, 2005.

. "Heidegger y el problema de la nada. La crítica a la posición de Nietzsche". In:

Pensamiento. Vol. 63 (2007), n. 235.

. "La crítica de Nietzsche al Romanticismo". In: Estudios Nietzsche. Revista de la

Sociedad Española de Estudios sobre F. Nietzsche. Número 5 (2005).

AZORÍN, J.R.M. Confesiones de un pequeño filósofo. Madri:Espasa-Calpe, 1981.

BAROJA, Pío. "Nietzsche y la filosofía". In: Revista Nueva 1899, 15 de Fevereiro e 5 de Agosto.

. "Nietzsche íntimo". In El Imparcial 1901, 9 de Setembro e 7 de Outubro.

"El éxito de Nietzsche". In: El Globo, Dezembro de 1902.

BARRIOS, M. La voluntad de poder como amor. Barcelona: Serbal, 1990.

. Hölderlin y Nietzsche: Dos paradigmas intempestivos de la modernidad en contacto. Sevilla: Universidad de Sevilla, 1992.

. Voluntad de lo Trágico: el concepto nietzscheano de voluntad. Madrid: Biblioteca

Nueva, 2002.

. “Expulsar de Nuevo al Poeta? de Arte y Política en Nietzsche”, In: Estudios

Nietzsche 2007 (7), pp.11-36.

. "Nietzsche y el Retorno Romántico a la Naturaleza", In: Estudios Nietzsche 2005 (5), pp. 33-66.

40 I Cad. Nietzsche, São Paulo, v.36 n.1, p. 17-44, 2015. 
- Narrar el Abismo: Ensayos sobre Nietzsche, Hölderlin y la disolución del clasicismo, Valencia: pré-textos, 2001.

BECERRO DE BENGOA, R. "Sobre Nietzsche”, In: La Ilustración española y americana, Madrid, Fevereiro de 1894.

BURGOS, E. Dioniso en la filosofía de joven Nietzsche. Zaragoza: Prensas Universitarias de Zaragoza, 1993.

."Mujer. Mujeres. Figuras polisémicas en la escritura de Nietzsche". In; Joan

B. Llinares (ed.), Nietzsche, 100 años después. Valencia: Pre-Textos, 2002, pp. 89-112.

- "Afirmando las diferencias. El feminismo de Nietzsche". In: Asparkía. Investigació Feminista, n 11, 2000, p. 77-93.

. "A propósito de la misoginia de Nietzsche". In: Laguna. Revista de Filosofía, $n^{\circ} 10,2002$, pp. 133-153.

. "La cuestión del sujeto. Nietzsche y Butler". In: Fina Birulés y María Isabel Peña Aguado (eds.), La passió per la llibertat, Universitat de Barcelona, 2004.

CANO, G. Como un ángel frío. Nietzsche y el cuidado de la libertad. Valencia: Pretextos, 2000; Nietzsche y la crítica de la modernidad. Madrid: Biblioteca Nueva, 2001.

CONILL, J. El crepúsculo de la metafísica. Barcelona: Anthropos, 1988

. El enigma del animal fantástico. Madrid: Tecnos, 1991.

. El poder de la mentira. Nietzsche y la política de la transvaloración. Madrid: Tecnos, 1997.

- "Recuperación postnihilista del individuo y la realidad: la metáfora del superhombre", Valencia: Quaderns de Filosofía y Ciencia, 1991, p. 7-17

ESTEBAN ENGUITA, J.E. Política y cultura en el pensamiento del joven Nietzsche (18691876), Universidad Autónoma de Madrid, 1999.

.Política, historia y verdad en la obra de F. Nietzsche, Universidad de BurgosHuerga \& Fierro, 2000.

. "Ecrasez l'infâme!". Cristianismo e historia en Nietzsche". In: Estudios Nietzsche $\mathrm{N}^{\circ} .6,2006,9-26$.

. "El aristocratismo político de Nietzsche". In: Cuaderno gris, $\mathrm{N}^{\circ} .5,2001$, 183-202.

GINER DE LOS RÍOS, F. "Nietzsche, fragmentos de un estudio sobre el anarquismo". Madrid, 1916.

IZQUIERDO, A. El resplandor de la apariencia: el concepto de cultura en Nietzsche. Madrid: Libertarias Produfi, 1993.

. Friedrich Nietzsche o el experimento de la vida. Madrid: Edaf, 2001.

LLINARES CHOVER, J.B. Hombre, arte y lenguaje. Una investigación sobre el joven Nietzsche. Servei de Publicacions de la Universitat de València,1982. 
Meca, D. S.

- "Nietzsche y el escepticismo. Ensayo aclaratorio de una pretendida contradicción”. In: Mirar con cuidado (J. Marrades y N. Sánchez, eds.), Valencia, pré-textos, 1994.

. "Nietzsche en los ensayos del poeta Gottfried Benn. Una aproximación". In: Nietzsche, 100 años después (ed. J. B. Llinares), Valencia, Pre-textos, 2002.

. "El teatro y la mujer en los escritos de F. Nietzsche sobre R. Wagner". In: L'ordim de la llar, Bari, Levante, 2003.

. "Consideraciones sobre la guerra en Nietzsche". In: La guerra (Edición de Nicolás Sánchez), Valencia, Pre-textos, 2006.

LYNCH, E. Dioniso dormido sobre un tigre: A través de Nietzsche y su filosofía del lenguaje. Barcelona: Destino, 1993.

MAEZTU, R., Hacia otra España. Bilbao, Biblioteca Bascongada de Fermín Herrán, 1899 (tomo 32).

MARAGALL, J. “Nietzsche”. In: L'Avenc, Barcelona: Julho de 1893.

MORENO, Luis Jiménez. El pensamiento de Nietzsche. Barcelona: Labor, 1971. . El pensamiento de Nietzsche. Madrid: Cincel, 1984.

ORTEGA Y GASSET, J., "Pío Baroja: anatomía de un alma dispersa”. In: Obras Completas, ed. Revista de Occidente, Madrid, Vol. IX, 1962, pp. 477-500.

. "Teoría del clasicismo II" (1907). In: Obras Completas, ed. Revista de Occidente, Madrid, Vol. I, 1962, pp. 68-75.

."El sobrehombre". In: Obras Completas, ed. Revista de Occidente, Madrid, Vol. I, 1962, pp.91-95.

PARMEGGIANI, M. Perspectivismo y subjetividad en Nietzsche. Málaga: Univ. de Málaga, 2002.

. Nietzsche: Crítica y proyecto desde el Nihilismo. Málaga: Ágora, 2002.

. "Interpretación y textualidad en la aproximación de Heidegger a Nietzsche",

In: S. Barbera - R. Müller-Buck (eds.), Nietzsche nach dem ersten Weltkrieg, Pisa: Edizioni ETS, 2007.

PÉREZ, Héctor J. Hacia el nacimiento de la tragédia. Murcia: Res Publica, 2001. . Nietzsche y la política. Murcia: Res Publica, 2001.

PUJANTE, D. Un vino generoso: sobre la estética nietzschiana. Universidad de Murcia, 1997.

QUESADA, J. Un pensamiento intempestivo: Ontología, estética y política en Nietzsche, Barcelona: Anthropos, 1988.

ROMERO CUEVAS, J.M. El caos y las forma. Granada: Comares, 2001.

RUIZ CALLEJÓN, E. Nietzsche y la filosofía prática. Granada: Universidad de Granada, 2004.

42 I Cad. Nietzsche, São Paulo, v.36 n.1, p. 17-44, 2015. 
. El Nihilismo activo. Genealogía de la Modernidad. México: Universidad de Guadalajara, 1999.

. La Belleza y los humillados. Barcelona: Ariel, 2001.

SÁNCHEZ MECA, D. En torno al superhombre: Nietzsche y la crisis de la modernidad.

Barcelona: Anthropos, 1989;

. “¿Quién es el superhombre de Nietzsche? El juego de las adivinanzas”, In:

SÁNCHEZ MECA, D., Metamorfosis y confines de la individualidad. Madrid:

Tecnos, 1995, pp. 137-198.

. Nietzsche: la experiencia dionisíaca del mundo. Madrid, Taurus, 2005.

- El nihilismo: perspectivas sobre la historia espiritual de Europa. Madrid:

Síntesis, 2004.

. "Voluntad de poder e interpretación como supuestos de todo proceso orgánico".

In: Estudios Nietzsche 2009 (9), pp.105-122.

. "Nietzsche y la idea romántica de una nueva mitología". In Estudios Nietzsche 2005 (5), pp. 129-152.

- "Razones de la moral y exigencias de la vida: Kant contra Nietzsche", In:

Daimon. Revista de Filosofía, 2004 (33), p. 157-166.

_."Généalogie et critique de la philologie aux sources de Choses humaines. trop humaines", In: D’Iorio, P.-Ponton, O. (eds.), Nietzsche. Philosophie de l'esprit libre, Paris, Editions rue d'Ulm, 2004, pp.79-98.

SANTIAGO, Luis de. Arte y poder. Aproximación a la estética de Nietzsche. Madrid: Trotta, 2004.

. "Nietzsche y los ideales estéticos del Sur: la necesidad de mediterraneizar la música". In: Analecta Malacitana, n 23/1, 2000, p.p 131-148.

. "Metáfora versus concepto. La generalización de la metáfora en F. Nietzsche". In: Estudios filosóficos 49 (2000), pp. 261-275.

- "La risa y el 'consuelo intramundano': el arte de trascenderse y superarse en Nietzsche”. In: Estudios Nietzsche 1 (2001), pp. 145-168.

- "Cosima Wagner y F. Nietzsche: claves para la interpretación de una relación enigmática. Correspondencia”. In: Estudios Nietzsche 7 (2007). Madrid: Trotta, pp. 155-202.

SAVATER, F. Inventario. Madrid: Taurus, 1973.

. Nihilismo y acción. Madrid: Taurus, 1971.

. Conocer Nietzsche y su obra. Barcelona: Dopesa, 1979.

. Idea de Nietzsche. Barcelona: Ariel, 2000.

SOBEJANO, G. Nietzsche na Espanha. Madrid: Gredos, 1967.

. "Reflejos de Nietzsche en el mundo hispánico". In: Revista de Occidente de 1973 (125-126). 
Meca, D. S.

. "Sobre la recuperación de Nietzsche". In: Revista de Occidente, 1973 (125126), p. 244.

UNAMUNO, M., "Voltaire, Rousseau, Nietzsche". In Contra esto y aquell. Buenos Aires: Espasa-Calpe, 1950.

URALES, F. La evolución de la filosofía en España. Barcelona: Ed. Cultura Popular, 1968.

VERMAL, J.L., La crítica de la metafísica en Nietzsche. Barcelona: Anthropos, 1987.

. "Acerca de la superación nietzscheana de la metafísica". In Nietzsche actual e inactual. Buenos Aires: 1994.

" "Nietzsche, el último metafísico". In: Revista de Occidente, 226 (2000).

.”¿Quién es el Nietzsche de Heidegger?”. In: Estudios Nietzsche, 1 (2001).

Artigo recebido para publicação em 15/08/2014.

Artigo aceito para publicação em 17/11/2014.

44 I Cad. Nietzsche, São Paulo, v.36 n.1, p. 17-44, 2015. 